\title{
Minimally invasive fetoscopic interventions: an overview in 2010
}

\author{
Thomas Kohl
}

Received: 21 April 2009/ Accepted: 14 August 2009/Published online: 17 March 2010

(C) The Author(s) 2010. This article is published with open access at Springerlink.com

\begin{abstract}
Background The availability of high-end endoscopic equipment, microcatheters, miniballoons, tiny laser fibers, and other devices has been instrumental in the development of minimally invasive fetoscopic interventions. These interventions are performed for a spectrum of fetal disease states that progress in severity over the course of gestation and have a huge impact on termination of pregnancy rates, fetal demise, perinatal mortality and morbidity, and longterm prognosis. This report aims to introduce interested readers to these new procedures.

Methods Fetoscopic interventions such as laser coagulation of pathologic placental vascular connections in twinto-twin-transfusion-syndrome, fetal biopsies, fetal tracheal balloon occlusion in diaphragmatic hernia, perforation of posterior urethral valves, tracheal decompression in fetal laryngeal atresia, and even coverage of spina bifida aperta can be performed by percutaneous minimally invasive fetoscopic techniques.

Results In contrast to prenatally untreated patients, the majority of patients who underwent fetoscopic interventions followed by state-of-the-art neonatal intensive care experienced improved survival rates and enhanced quality of life. Yet for some patients, significant morbidity from the underlying disease or fetal surgical complications, most often early preterm delivery, persist in postnatal life.
\end{abstract}

T. Kohl $(\bowtie)$

German Center for Fetal Surgery and Minimally Invasive Therapy, Department of Obstetrics and Prenatal Medicine, University of Bonn, Sigmund Freud Strasse 25,

53105 Bonn, Germany

e-mail: thomas.kohl@ukb.uni-bonn.de

URL: www.uniklinik-bonn.de/dzft
Conclusion A growing spectrum of fetal disease states has become amenable to minimally invasive fetoscopic interventions. Sufficient training, an interdisciplinary approach, ethical board supervision, and continued scientific assessment of benefits and risks are important for the success and acceptance of these procedures. Further improvements in fetal selection, surgical techniques, and postnatal management accompanied by the development of specialized devices are desired.

Keywords Amniotic band constriction . Diaphragmatic hernia $\cdot$ Fetal surgery $\cdot$ Fetoscopy ·

Minimally invasive $\cdot$ Posterior urethral valves . Prenatal medicine syndrome $\cdot$ Spina bifida Twin-to-twin transfusion

Fetal surgery aims to improve the poor prognoses of human fetuses affected by a spectrum of disease states that progress in severity over the course of gestation and have a huge impact on termination of pregnancy rates, fetal demise, perinatal mortality and morbidity, and long-term prognosis.

Lacking minimally invasive tools at the time, Michael Harrison and other investigators introduced open fetal surgery requiring maternal laparotomy and hysterotomy in the early 1980s [1]. Until today, the open fetal surgical approach is performed for some fetal surgical procedures, most commonly fetal spina bifida repair [2]. To reduce the maternal trauma from the open fetal surgical approach, minimally invasive fetoscopic procedures are being developed.

After fetoscopy first became available in about 1970, its clinical role for many years remained mostly confined to diagnostic purposes because image quality, particularly the 
lack of video cameras, put a lid on the development of more complex orchestrated procedures [3]. Since then, the availability of high-end endoscopic equipment as well as microcatheters, miniballoons, tiny laser fibers, and other devices has prompted the systematic development of minimally invasive fetoscopic interventions by a small number of teams around the world. As a consequence, fetoscopic procedures have become feasible [4-10], as have laser coagulation of pathologic placental vascular connections in twin-twin transfusion syndrome, fetoscopic umbilical cord ligation to prevent neurologic injury or demise in discordant monochorionic twins or twin-reversed arterial perfusion (TRAP), fetal tracheal balloon occlusion in diaphragmatic hernia, fulgurization of posterior urethral valves, tracheal decompression in fetal laryngeal atresia, and even coverage of spina bifida aperta over the past one and a half decades.

\section{Maternal and fetal pain management monitoring and tocolysis}

Infiltration of the maternal abdominal and uterine wall with local anesthetics provides sufficient maternal analgesia during most single-trocar fetoscopic procedures such as laser ablation of placental vessels or fetal tracheal balloon occlusion. Intraumbilical or direct fetal intramuscular administration of opioid analgesics and muscle relaxants suffices for most invasive procedures performed on the fetus. Only lengthy and complex procedures such as fetoscopic surgery for fetal spina bifida require general materno-fetal anesthesia. Standardized protocols ensure both patient safety and technical success $[11,12]$.

In contrast to previous assumptions, tocolytic requirements usually are minimal during the perioperative period of most minimally invasive fetal interventions. Either no tocolysis at all or only a one-time administration of either indomethacin or nifedipin, sometimes accompanied by infusion of the oxytocin antagonist atosiban, is used at our center. Notably, in monochorionic twin gestations affected by the twin-to-twin transfusion syndrome, indomethacin may prompt dangerous degrees of ductus arteriosus constriction [13].

Patients requiring more intense tocolysis usually are the ones who exhibit marked polyhydramnios resulting in uterine contractions, abdominal pain, cervical shortening, vaginal bleeding, and even increased C-reactive protein levels before fetal intervention. Therefore, not surprisingly, a massive polyhydramnios before fetal surgery accompanied by the aforementioned signs and symptoms has been the most important risk factor for perioperatively adverse outcomes at our center.

\section{Maternal and fetal safety}

In contrast to open fetal surgery, the minimally invasive fetoscopic approaches largely decrease maternal and fetal morbidity. Nevertheless, despite the use of small-caliber trocars, bleeding complications from vascular or placental injuries, separation of chorioamniotic membranes, amniotic fluid leakage, chorioamnionitis, or early preterm delivery must be expected to occur for some patients. Nevertheless, the majority of fetuses undergoing fetoscopic interventions, including those undergoing spina bifida repair via three trocars, currently are born beyond 32 weeks of gestation. At this gestational age, the risks from immaturity become so low that the benefits of the prenatal intervention may outweigh its risks.

\section{Intraamniotic access}

Currently, most fetoscopic interventions can be performed entirely by a percutaneous approach. Percutaneous intraamniotic access is facilitated by satisfactory ultrasound image quality, a not too obese maternal abdominal wall, and a favorable placenta position [14-16]. Depending on the operative goal, one to three trocars are placed into the amniotic cavity (Fig. 1). External trocar diameters usually range from 3 to $5 \mathrm{~mm}$.

\section{Partial amniotic carbon dioxide insufflation}

During complex fetoscopic surgical interventions, such as those for spina bifida aperta that require tissue dissection and resection, the amniotic fluid continuously gets tainted by small amounts of blood. In this setting, only partial

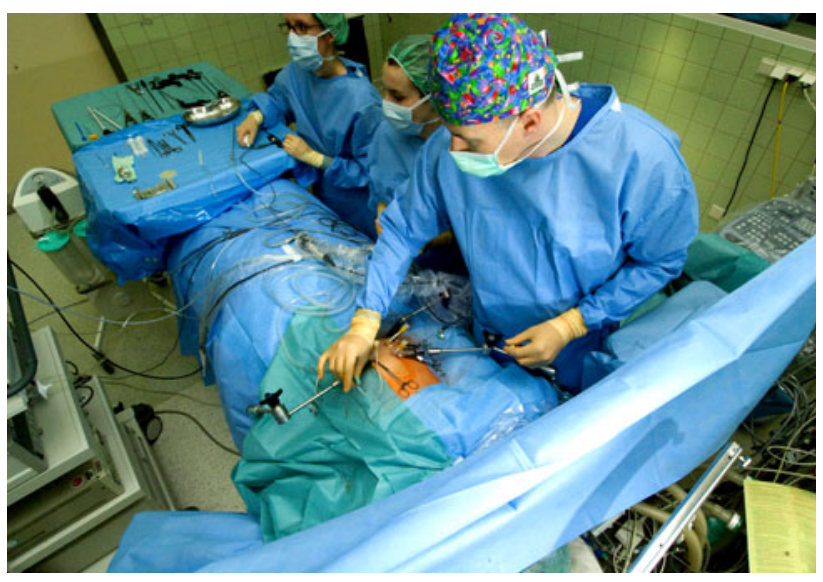

Fig. 1 Typical operating room setup for fetoscopic surgery at the author's center. In this case, fetoscopic closure of fetal spina bifida was performed, requiring a three-trocar approach 
insufflation of the amniotic cavity is needed to maintain adequate visualization throughout the entire procedure (Fig. 2).

Both technical and safety aspects of amniotic gas insufflation have been examined in sheep and humans, with conflicting safety results $[15,17-23]$. Some investigators observed that in this species, carbon dioxide insufflation may result in fetal acidosis and demise. In contrast, our group did not show detrimental effects of amniotic gas insufflation with either compressed air or carbon dioxide on the postnatal neurologic status, behavior, or brain histology of sheep during fetoscopic interventions. Based on our personal experience from these experiments, carbon dioxide has become the insufflation medium of first choice at our center.
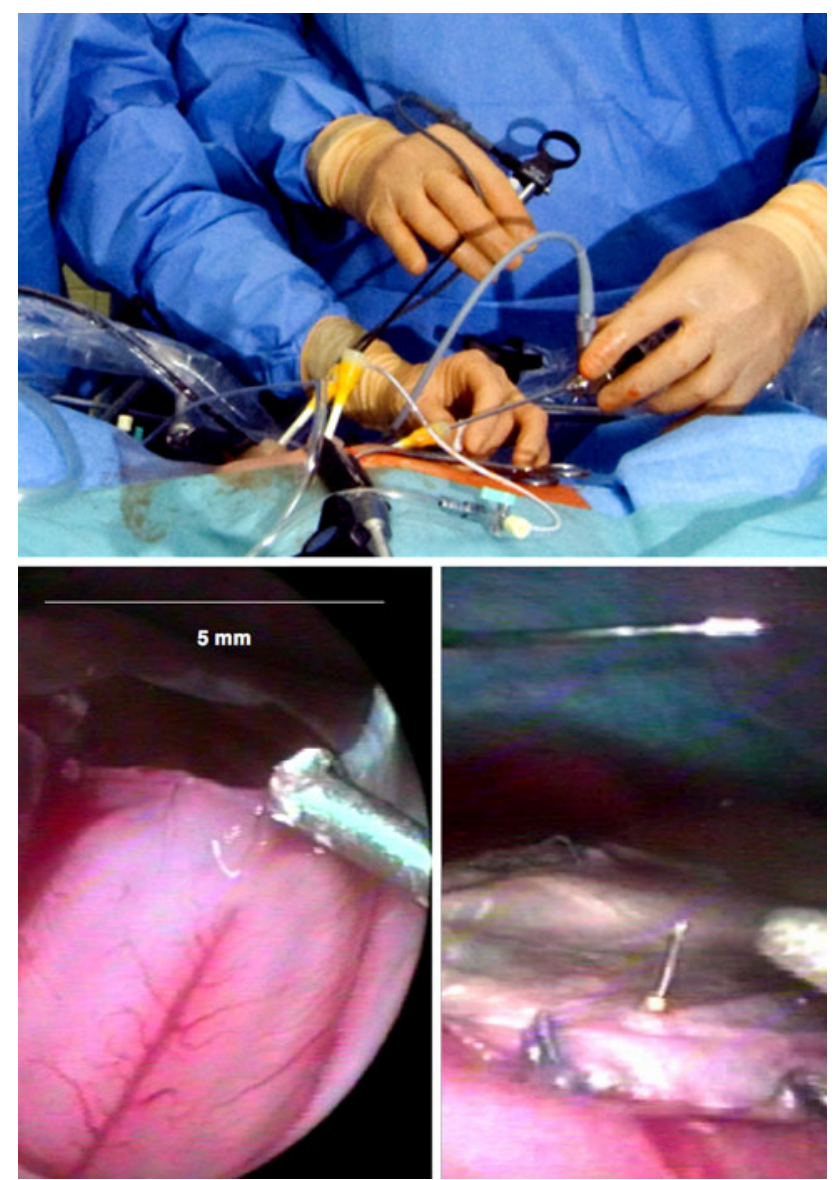

Fig. 2 During complex fetoscopic surgical interventions such as those for spina bifida aperta, only partial amniotic carbon dioxide insufflation (PACI) can maintain adequate visualization throughout the entire procedure. Top: Close-up view of instrument manipulations using a $3.7-\mathrm{mm} 30^{\circ}$ fetoscope via three trocars with an external diameter of $5 \mathrm{~mm}$. Bottom left: Superior visibility offered by PACI during dissection of the neural placode using a specially developed microknife. Bottom right: After removal of pathologic tissues, the neural tissue is covered by an absorbable patch
At the time of this report, we had safely used partial amniotic carbon dioxide insufflation (PACI) during 51 human fetoscopic surgical procedures, for which efforts at obtaining sufficient visualization would have been too time consuming or impossible with conventional means [24]. Nevertheless, because of this still very limited clinical experience with PACI, continued assessment of its risks, safety margins, and management issues accompanied by serial postnatal patient follow-up evaluation using standardized development tests is desired.

\section{Fetoscopic interventions}

\section{Diagnostic fetoscopy}

The simplest fetoscopic procedures are diagnostic fetoscopies. For example, a fetal muscle or skin biopsy can be performed to rule out Duchenne muscular dystrophy or Harlekin ichthyosis. These procedures usually are well tolerated by the patient under maternal local anesthesia and fetal analgo-sedation. At many centers, less invasive ultrasound-guided biopsies have entirely replaced the fetoscopic approach.

Fetoscopic laser coagulation in the treatment of twin-twin transfusion syndrome

Severe twin-twin transfusion syndrome (TTTS) occurs in about $10 \%$ of monochorionic twin gestations. Untreated, the disease commonly results in the demise of both fetuses [25]. Because monochorionic twins share a single placenta, the circulation of one of the twins, the so-called "donor," becomes compromised by blood and pressure loss via arteriovenous anastomoses toward its sibling twin, the socalled "recipient." Additional venovenous or arterioarterial anastomoses that modify the disease course and severity also can be observed [26, 27].

On the other hand, the transfer of renin released by both the hypotensive, hypovolemic donor and the placenta favor the development of hypervolemia, hypertension, polyuria, cardiac failure, and abnormal fetoplacental blood flow in the recipient twin [28, 29]. Fetoscopic laser photocoagulation of abnormal placental vessels in TTTS has been developed and clinically introduced by de Lia et al. [4, 30] (Fig. 3). With some modifications as to where the pathologic vessels should be targeted on the placental surface [31], this approach has become the most commonly performed and tested fetoscopic procedure worldwide.

The results of a randomized trial by the Eurofetus group have proved that fetoscopic laser ablation is superior to serial amnioreduction in improving outcome [32]. In short, after fetoscopic laser ablation, the survival of at least one 

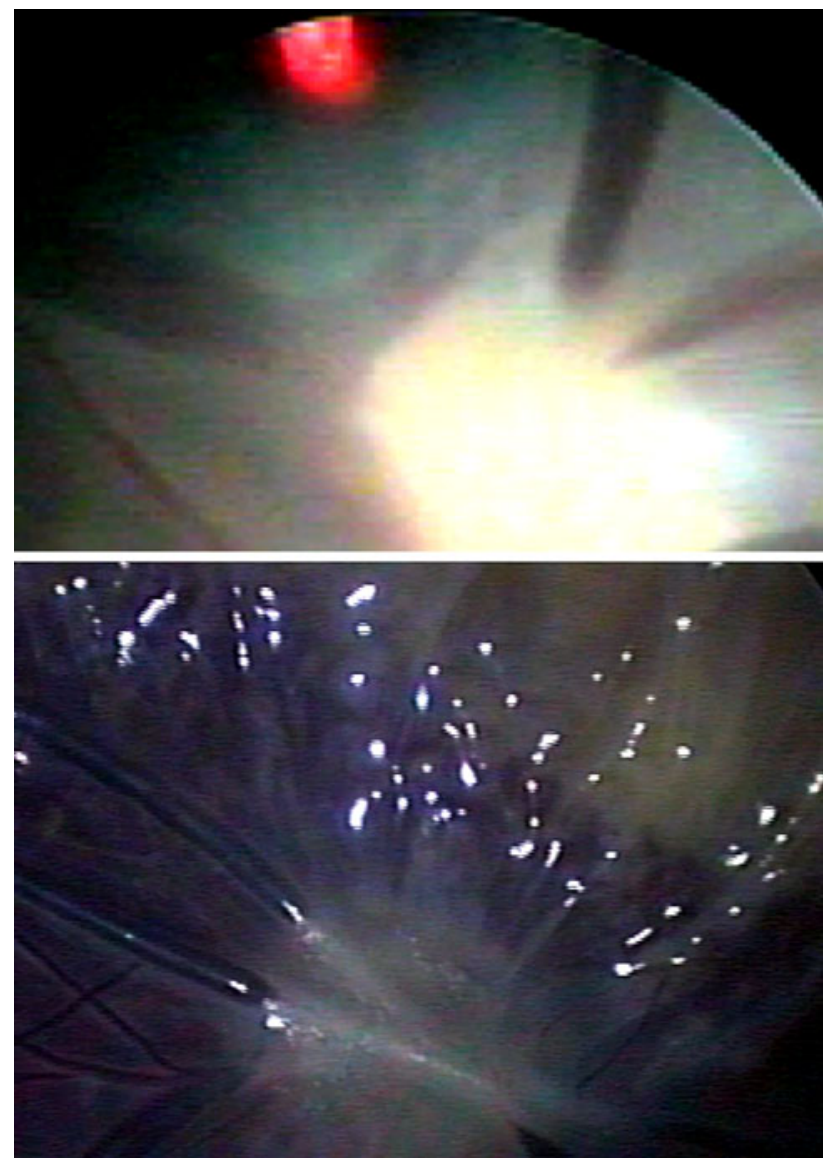

Fig. 3 Fetoscopic laser photocoagulation of abnormal placental vessels in twin-twin transfusion syndrome. The percutaneous procedure is performed with the patient under local anesthesia via a single trocar or after direct insertion of the fetoscope shaft. Most often, laser ablation of pathologic vessels on the placental surface is performed within amniotic fluid (top). For cases in which adequate visualization of an anterior placenta within blood-stained or turbid amniotic fluid is difficult, partial amniotic carbon dioxide insufflation (PACI) is used at the author's center (bottom)

twin can be expected in about $80 \%$ of cases and the survival of both twins in about half of cases. Most fetuses currently are born beyond 30 weeks of gestation, and the incidence of neurologic damage in survivors is low. Preoperative staging of affected fetuses is most commonly performed by a system developed by Quintero et al. [33].

Based on a recent metaanalysis, fetoscopic laser ablation may now be considered for treating all stages of TTTS [34], yet further research investigating the effect of this treatment on milder stages is recommended. The procedure is performed with the patient under local anesthesia via a single trocar or after direct insertion of the fetoscope shaft using a stab trocar. For cases in which adequate visualization of an anterior placenta within blood-stained or turbid amniotic fluid is difficult, PACI is used at our center [35]. At the end of the procedure, excess amniotic fluid is drained, resulting in immediate improvement of maternal discomfort.

Fetoscopic laser ablation of posterior urethral valves

Total bladder outlet obstruction by posterior urethral valves before 20 weeks of gestation usually results in bilateral kidney destruction and due to the concomitant lack of amniotic fluid in severe pulmonary hypoplasia [36]. Prenatal intervention for this condition currently is most often performed by ultrasound-guided percutaneous shunt insertion for bladder drainage. Limited evidence from a systematic review and metaananalysis suggests that this approach may improve perinatal survival for affected fetuses, particularly those with poor predicted prognoses [37]. The University of Birmingham's PLUTO (percutaneous shunting in lower urinary tract obstruction) trial aims to provide more robust evidence by conducting a prospective randomized multicenter investigation with a subgroup of affected fetuses [38].

As an alternative to vesico-amniotic shunt insertion, Quintero et al. [8] were the first to demonstrate the feasibility of therapeutic fetal cystoscopy and endoscopic fulguration of posterior urethral valves. Since then, posterior valve ablation has been performed by various groups for a larger number of patients, albeit with limited success [3941]. Within the same anatomic region, endoscopic fetal urethrotomy for anterior urethral valves also has been described [42]. Recent technical modifications aim to facilitate fetoscopic bladder entry and overcome access to the proximal urethra from physiologic angulation of the bladder neck [43].

Unfortunately, ultrasound examination and serial analysis of fetal urine samples before fetal intervention remain unreliable for differentiating between groups of fetuses that may or may not benefit from fetal intervention [44-47]. Therefore, further research is needed to improve fetal selection for intervention and to perform it earlier in the gestation period.

Fetoscopic lysis of amniotic bands

Amniotic bands constricting a fetal limb or the umbilical cord may result in loss of extremity function or fetal demise [48, 49]. After studies with fetal sheep demonstrating the potential for functional recovery of affected extremities after debanding [50], Quintero et al. [51] performed the first fetoscopic lysis of amniotic bands in human fetuses. Since then, the procedure has been performed for small numbers of human fetuses with variable success [52] (Fig. 4).

From our own limited experience with three fetuses, we assume that Doppler ultrasound demonstration of both 

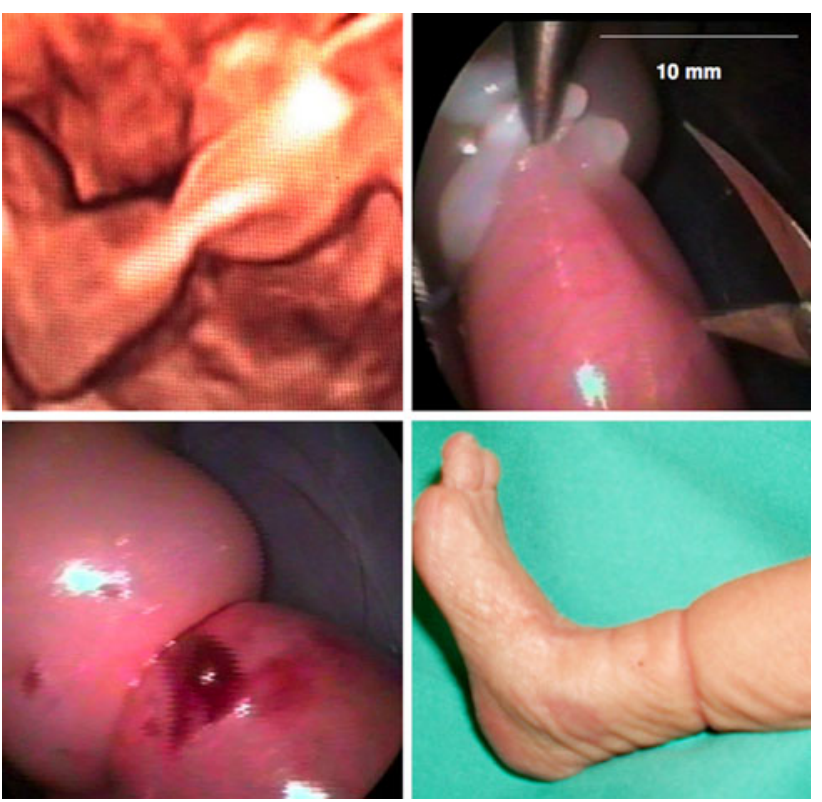

Fig. 4 Amniotic bands constricting a fetal limb or the umbilical cord may result in loss of extremity function or fetal demise. Top left: Three-dimensional ultrasound image exhibiting severe constriction of the distal third of the left calf in an unborn fetus at $21+1$ weeks of gestation. Top right: Fetoscopic view during transection and removal of the band in the gas-insufflated amniotic cavity. Bottom left: Fetoscopic aspect after removal of the band. Pink skin coloration distal to the obstruction site allows assumption of preserved microvascular blood flow. Bottom right: After delivery, near normal contour and function of the left foot were observed. (Color figure online)

arterial and venous wave forms accompanied by active muscle movements distal to the constriction indicate fetuses with limb constriction that may benefit from band removal [53].

Fetoscopic tracheal balloon occlusion in fetuses with diaphragmatic hernia

Herniation of abdominal organs into the fetal chest results in life-threatening pulmonary hypoplasia for about half of prenatally detected fetuses with congenital diaphragmatic hernia. Attempts at open fetal surgery to close the diaphragmatic defect during gestation did not improve survival for the most severely affected fetuses and impaired outcome in the less severe cases [54]. Alternatively, the therapeutic concept of fetoscopic tracheal occlusion was developed and introduced clinically [55, 56].

After tracheal occlusion, the pressure buildup from fluid normally released by the lung to maintain airway patency and promote pulmonary development throughout gestation results in lung distension and hyperplasia. Quintero et al. [7] were the first to report percutaneous single-trocar fetoscopic tracheal occlusion in a human fetus. Since then, the technique has been refined further in animal studies [57-59]. Like other single-trocar techniques, percutaneous fetoscopic tracheal balloon occlusion can be performed using maternal local anesthesia combined with fetal analgo-sedation and relaxation (Fig. 5). Fetal selection is based on ultrasound assessment of liver position, the so-called lung-to-head ratio, and/or determination of fetal lung volume by magnetic resonance imaging [60-62].

For awhile, the results of a National Institutes of Health (NIH)-sponsored prospective randomized clinical trial carried out at the University of California at San Francisco (UCSF) stirred confusion about the value of the described approach [63]. The trial was prematurely abandoned when fetal tracheal occlusion had not improved outcome

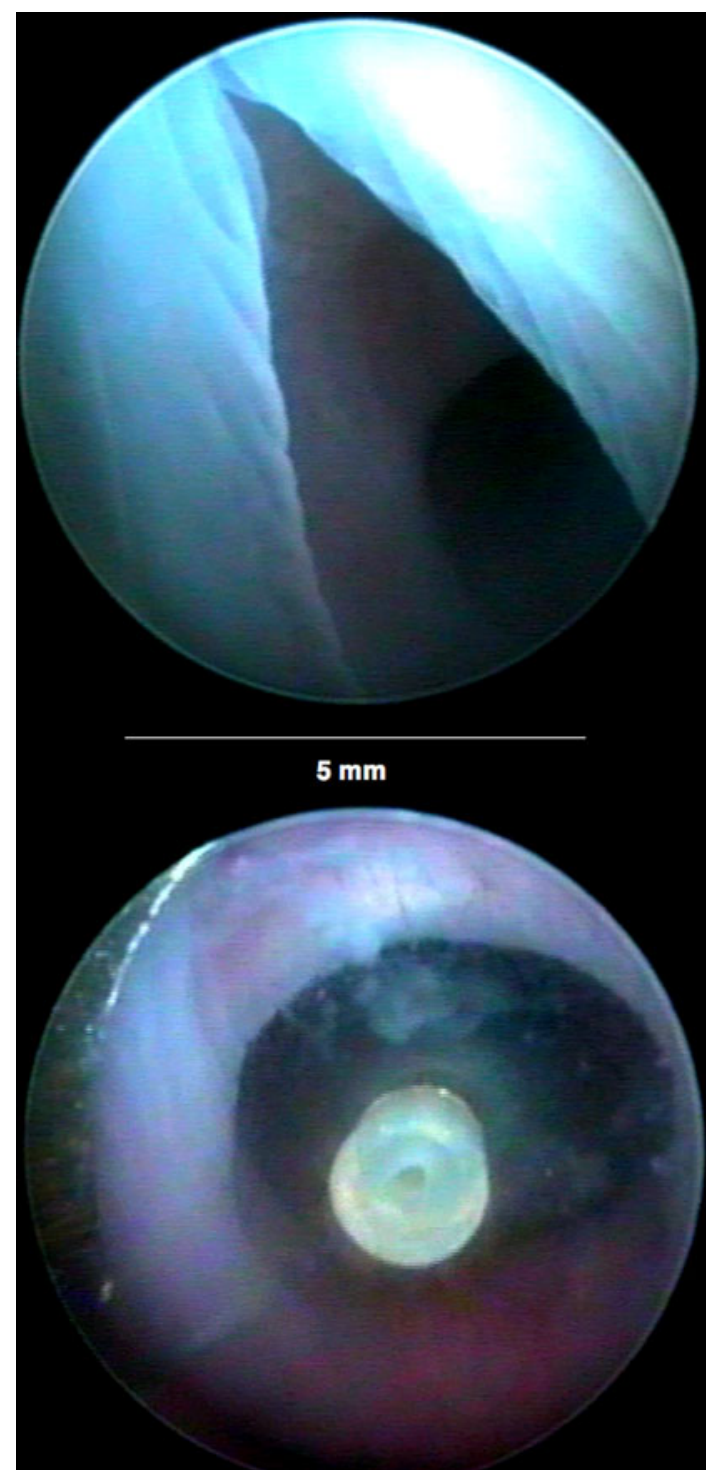

Fig. 5 Fetoscopic images during fetoscopic tracheal occlusion in a late gestation fetus with severe diaphragmatic hernia. Fetoscopic view using a 2-mm rod-lens endoscope in the fetal trachea before (top) and after (bottom) balloon insertion 
compared with postnatal intensive care therapy offered in this highly specialized center. Although obvious to the specialist reader, most readers seemed to miss that the study cohort included a marked proportion of less severely affected fetuses and that early preterm premature delivery also may have had an impact on the poor outcome in the occlusion group.

Following an effective international recruitment strategy, the Eurofetus consortium recently published their sobering experience with fetoscopic tracheal balloon occlusion in 210 cases with severe diaphragmatic hernia [64]. In these fetuses, the group achieved survival rates of $49 \%$ for severely affected fetuses with left and $35 \%$ of fetuses with right diaphragmatic hernia. Hinting to severe logistical problems at the time of delivery, 10 deaths alone could be directly attributed to difficulties with balloon removal. In addition, following tracheal occlusion at a mean gestational age of 27.1 weeks, $30 \%$ of cases where born prior to 34 weeks. At this gestational age, poor outcomes can be expected due to the more immature lungs and because extracorporeal membrane oxygenation is usually not an option.

Whereas Harrison et al. [63] already had speculated from their trial that early preterm delivery after fetoscopic tracheal occlusion might offset the beneficial effects of the intervention on pulmonary growth and function, further debate concerning the timing and duration of the occlusion period ensued between the European groups [65, 66]. Based on the UCSF and the Eurofetus experience and the ever growing body of experimental studies on fetal tracheal occlusion, our group introduced the strategy of deliberately delayed fetoscopic tracheal balloon occlusion [67]. The first goal of this strategy was to prevent entirely iatrogenic preterm delivery of immature fetuses with diaphragmatic hernia by postponing the intervention to beyond 30 weeks of gestation. The second goal was to achieve a gestational age at delivery that enabled these frail infants to be provided all means of intensive care therapy, particularly extracorporeal membrane oxygenation (ECMO). In addition, we reduced the occlusion period before removal of the balloon again by fetoscopy to between 8 and 14 days. Yet after application of our deliberately delayed and much shorter fetoscopic tracheal occlusion approach in sixteen fetuses with isolated left diaphragmatic hernia, only six (37\%) survived to discharge. Adding to the frustration, one death resulted from anesthetic problems and three from balloons dislodging within the first three days of treatment. In these cases, two mothers opted against reintervention and one for termination of pregnancy. Our recent efforts in order to improve outcome in this subset of fetuses have resulted in the development of a more reliable occlusion device and in further postponing occlusion such that treated fetuses are born even nearer to term.
As neither in the similar sized control group nor in the failing-balloon group a single fetus with left diaphragmatic hernia has survived despite the postnatal availability of ECMO, I believe that the poor survival also reflects the selection of severest cases. In contrast, we observed an impressive survival rate in a small series of fetuses with right diaphragmatic hernia undergoing temporary tracheal occlusion at our center. Seven of eight fetuses $(87 \%)$ with isolated right diaphragmatic hernia survived postnatal treatment to discharge. We attribute the markedly higher survival rates following the delayed approach in right diaphragmatic hernia to delivery of treated fetuses between 35 and 38 weeks of gestation, the regular availability of extracorporeal membrane oxygenation (ECMO) on the first day of life and despite smaller lungs to begin with the intrinsic property of more normally developed pulmonary vessels that vasodilate during materno-fetal hyperoxygenation in the right-sided condition.

In the meantime, the deliberately delayed and shortened approach to fetoscopic tracheal balloon occlusion has also been adopted for a current randomized trial protocol by Eurofetus, with the balloon placed at 30-32 +6 weeks of gestation and removed at 34-35+6 weeks of gestation [68]. In our own randomized trial, we assess the value of the delayed approach in relation to a variety of postnatal treatment aspects for fetuses with less severe left diaphragmatic hernia [69]. Despite the availability of similar data previously published by Eurofetus for much larger cohorts of fetuses [70], an unblinded, nonrandomized trial by the pioneering fetal treatment center at UCSF simply focuses on fetal lung growth after successful tracheal occlusion by serial ultrasound assessment of the lung-to-head ratio [71].

Fetoscopic tracheal occlusion in fetuses with severe pulmonary hypoplasia from early preterm premature rupture of membranes

Early preterm premature rupture of membranes (ePPROM) before 22 weeks of gestation affects thousands of pregnant women throughout the world each year. Amniotic fluid loss often is so severe that anhydramnios occurs. It is in these cases that chronic external compression of the fetal chest from the uterine wall and marked upward displacement of the diaphragm by the liver interfere with normal lung development. Pulmonary hypoplasia may become so severe that chances of postnatal survival are poor [72].

Based on an analysis of 31 fetuses, Laudy et al. [73] calculated a positive predictive value of $86 \%$ for the development of lethal pulmonary hypoplasia when preterm premature rupture of membranes occurred at or before 20 weeks of gestation followed by 8 weeks or more of oligohydramnios and the degree of oligohydramnios was $1 \mathrm{~cm}$ or less. 
Experimental treatments such as the amniopatch procedure or serial amnioinfusions have been ineffective in restoring adequate amounts of amniotic fluid in many pregnancies with spontaneously occurring ePPROM [7476]. Therefore, based on the observation from ovine studies that experimental fetal tracheal ligation prevents pulmonary hypoplasia associated with fetal nephrectomy [77], we performed percutaneous fetoscopic tracheal balloon occlusion between $27+6$ and $28+3$ weeks of gestation in three fetuses with severe fetal pulmonary compression/ hypoplasia from ePPROM [78, 79]. In each case, tracheal occlusion resulted in stunningly fast improvements in lung volume and survival.

Fetoscopic surgery for fetal laryngeal atresia

Near total to total occlusion of the fetal larynx or trachea is rarely observed. In about half of fetuses, this malformation occurs in association with Fraser syndrome [80]. Concomitant congestion of pulmonary fluid inside the fetal tracheobronchial tree causes massive distension and hyperplasia of the lungs as well as cardiac failure. For this sequence of events, the telling acronym CHAOS (congenital high-airway obstruction syndrome) has been coined. For affected hydropic fetuses, CHAOS has been almost uniformly fatal, yet some have been salvaged by elective preterm delivery using the ex utero intrapartum (EXIT) procedure [81, 82].

In fetal sheep with iatrogenic CHAOS, prenatal opening of the airway obstruction led to reversal of hydropic changes [83]. Based on these findings and the poor natural history of the syndrome, we performed percutaneous fetoscopic tracheal decompression in two hydropic human fetuses with laryngeal atresia and CHAOS at about 20 weeks of gestation (Fig. 6) [9, 84]. Fetal cardiac filling, diaphragmatic function, lung hyperechogenicity, and the cardiothoracic area ratio progressively normalized as a result of the percutaneous fetoscopic intervention. Both infants survived to discharge from the hospital.

\section{Fetoscopic spina bifida repair}

Fetal surgery on unborns with spina bifida aims to protect the exposed neural tissue from amniotic fluid, fetal stool, and mechanical stress and to reduce hindbrain herniation $[85,86]$. After studies with sheep, the first fetoscopic approaches for spina bifida closure in humans by maternal laparotomy, uterine exteriorization, and transuterine trocar placement were reported in the United States by Bruner et al. and Farmer et al. [23, 87-89]. Yet both teams abandoned their fetoscopic approaches because early results were disappointing due to technical difficulties.
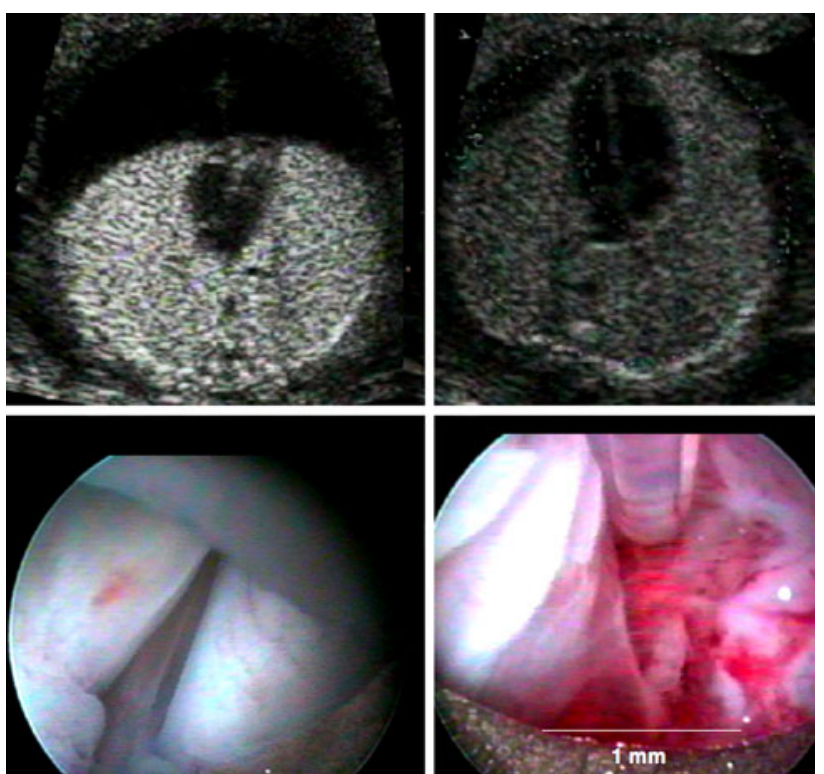

Fig. 6 Sonographic and fetoscopic findings in a human fetus with congenital high-airway obstruction syndrome (CHAOS) from laryngeal atresia at $21+3$ weeks of gestation. Top left: Fetal ultrasound imaging in the four-chamber view depicts the typical findings of bilateral lung hyperechogenicity and enlargement as well as a small heart. Top right: Five days after fetoscopic tracheal decompression, improvement in fetal heart-lung size relationship and normalization of lung echogenicity can be observed. Bottom left: Fetal laryngoscopy using a $2-\mathrm{mm} 0^{\circ}$ rod-lens fetoscope confirms laryngeal atresia by a membrane seen beneath the vocal folds. Bottom right: To achieve fetal tracheal decompression, a laser fiber was advanced via the working channel of the fetoscope and placed above the atretic region. At this location, the fiber was activated and repositioned until four small $0.4-\mathrm{mm}$ openings were achieved

Since then, fetoscopic fetal surgery for spina bifida has been replaced by an open surgical approach performed currently for several hundreds of human fetuses in North America [89, 90] and also for some fetuses in Brazil, Poland, and Spain. Pending the results of a randomized trial (MOMS trial), the therapeutic potential of the open operation to improve leg, bladder, and bowel function and to reduce the severity of hindbrain malformation and hydrocephalus will remain controversially discussed [91-100].

To minimize maternal trauma from the open fetal surgical approach, after technical feasibility studies with inanimate models and sheep, our group reintroduced a percutaneous minimally invasive fetoscopic approach [10, 101]. Currently, the approach allows precise dissection of the placode, resection of pathologic tissues, and coverage of the malformation in layers such that neonatal neurosurgical repair currently has been obviated in already 10 cases (Fig. 2) [102, 103].

Probably because of more careful attention to membrane closure at the time of trocar removal than in earlier patients [104], most surgically treated fetuses currently are delivered at 32-35 weeks of gestation. From our early clinical experience in 25 human fetuses it appears that 
1. the quality of leg function (and also likely bladder and bowel function), present at the time of surgery can be preserved in these fetuses, regardless of lesion height,

2 . the fetoscopic procedure reliably results in improvements of hindbrain herniation, and

3. progressive ventricular dilatation and postnatal ventriculo-peritoneal shunt insertion can be avoided in most cases when the lateral ventricular width is $\leq 12 \mathrm{~mm}$ at the time of surgery.

Fetal cardiac interventions assisted by fetoscopy

Fetal cardiac interventions are being developed to improve the outcome and prognosis of fetuses with a spectrum of
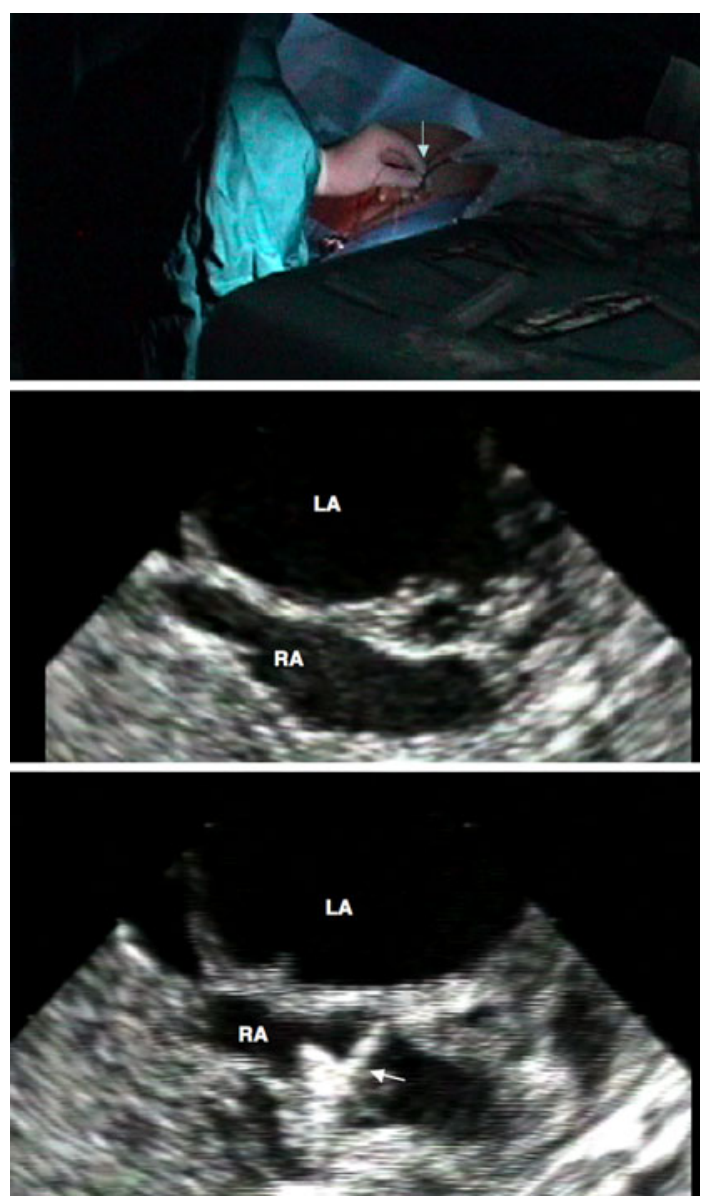

Fig. 7 Fetoscopic fetal transesophageal echocardiography (FFTEE) at $26+6$ weeks of gestation in a human fetus with a closed atrial septum and aortic atresia. Top: Ultrasound catheter insertion requiring a single trocar. Middle: The closed atrial septum and the hypoplastic aortic root can be identified clearly (LA, left atrium; RA, right atrium). Bottom: A microinstrument with opened jaw (arrow) can be seen directed against the septum. Such clear demonstration of an intracardiac interventional device usually is not possible with the conventional imaging approach cardiac malformations, most often severe semilunar valve obstructions [110]. During fetal balloon valvuloplasty, we found that fetoscopic fetal transesophageal echocardiography (FFTEE) permits substantially clearer definition of fetal cardiac anatomy and intracardiac device manipulation than conventional maternal transabdominal fetal echocardiography (Fig. 7) [105-108].

Most recently, fetoscopic transesophageal electrocardiography has become available a minimally invasive tool for cardiac monitoring, diagnostics and intervention in human fetuses with theray refractory fetal tachycardias [109].

Less invasive alternatives to other fetoscopic procedures

Fetoscopic procedures such as umbilical cord ligation (Fig. 8) in discordant monochorionic twins or in the twinreversed arterial perfusion (TRAP) sequence will most likely be replaced by technically far more simple and less invasive percutaneous ultrasound guided radiofrequency ablation of the umbilical vessels [110].

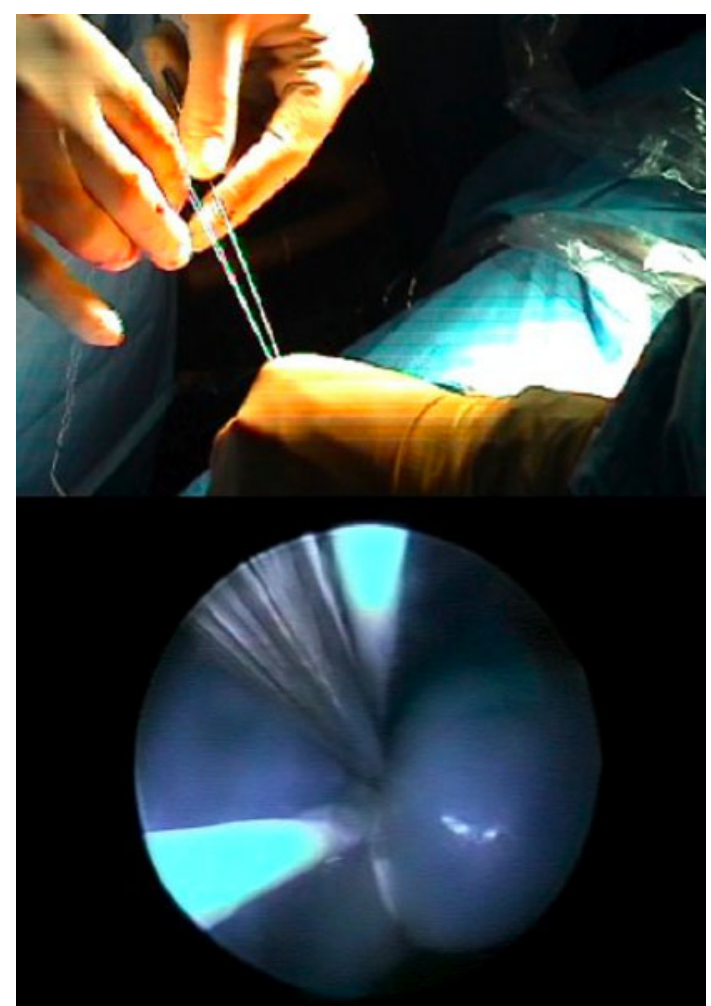

Fig. 8 Fetoscopic umbilical cord ligation in a discordant monochorionic twin pregnancy via a single trocar. Top: External aspect during knot pushing. Bottom: Clear demonstration of umbilical cord, ligature, and knot pusher during cord ligation in the gas insufflated amniotic cavity 


\section{Conclusion}

For an increasing spectrum of fetal malformations and disease states, minimally invasive fetoscopic techniques can now be offered. Nevertheless, because these procedures still rely heavily on equipment borrowed from other specialties, further development of specialized instrumentation and devices is required. Their efficacy for improving fetal outcome over that demonstrated by state-of-the-art postnatal treatment strategies requires further studies in dedicated centers.

Acknowledgments This report is cordially dedicated to Kristina Tchatcheva, who has over the past 5 years so often supported me with her infatigable camera skills during the most difficult fetoscopic prodedures. I thank the German Research Society (DFG) for funding my efforts to develop techniques for minimally invasive fetoscopic intervention by a whole series of grants since 1993 .

Disclosure Thomas Kohl is a consultant for Karl Storz Inc., Tuttlingen, Germany.

Open Access This article is distributed under the terms of the Creative Commons Attribution Noncommercial License which permits any noncommercial use, distribution, and reproduction in any medium, provided the original author(s) and source are credited.

\section{References}

1. Harrison M (2001) Historical perspective. In: Harrison MR, Evans MI, Adzick NS, Holzgreve W (eds) The unborn patient, 3rd edn. WB Saunders, Philadelphia, pp 11-18

2. Johnson MP, Sutton LN, Rintoul N et al (2003) Fetal myelomeningocele repair: short-term clinical outcomes. Am J Obstet Gynecol 189:482-487

3. Kohl T (2004) Fetoscopic surgery: where are we today? Curr Opin Anaesthesiol 17:315-321

4. De Lia JE, Cruikshank DP, Keye WR Jr (1990) Fetoscopic neodynium: YAG laser occlusion of placental vessels in severe twin-twin transfusion syndrome. Obstet Gynecol 75:1046-1053

5. Crombleholme TM, Robertson F, Marx G, Yarnell R, D'Alton ME (1996) Fetoscopic cord ligation to prevent neurologic injury in monozygous twins. Lancet 348:191

6. Quintero RA, Reich H, Pruder KS, Bardicef M, Evans MI, Cotton DB, Romero R (1994) Brief report: umbilical cord ligation to an acardiac twin by fetoscopy at 19 weeks of gestation. N Engl J Med 330:469-471

7. Quintero R, Morales W, Bernick PW, Allen MH, Johnson PK (2000) Minimally-invasive intraluminal tracheal occlusion in a human fetus with left congenital diaphragmatic hernia at 27 weeks' gestation via direct fetal laryngoscopy. Prenat Neonatal Med 5:134-140

8. Quintero RA, Hume R, Smith C, Johnson MP, Cotton DB, Romero R, Evans MI (1995) Percutaneous fetal cystoscopy and endoscopic fulguration of posterior urethral valves. Am J Obstet Gynecol 172:206

9. Kohl T, Hering R, Bauriedel G, Van de Vondel P, Heep A, Keiner S, Müller A, Franz A, Bartmann P, Gembruch U (2005) Percutaneous fetoscopic and ultrasound-guided decompression of the fetal trachea permits normalization of fetal hemodynamics in a human fetus with Fraser syndrome and congenital high airway obstruction syndrome (CHAOS) from laryngeal atresia. Ultrasound Obstet Gynecol 27:84-88

10. Kohl T, Hering R, Heep A, Schaller C, Meyer B, Greive C, Bizjak G, Buller T, Van de Vondel P, Gogarten W, Bartmann P, Knöpfle G, Gembruch U (2006) Percutaneous fetoscopic patch coverage of spina bifida aperta in the human: early clinical experience and potential. Fetal Diagn Ther 21:185-193

11. Hering R, Hoeft A, Putensen C, Tchatcheva K, Stressig R, Gembruch U, Kohl T (2009) Maternal haemodynamics and lung water content during percutaneous fetoscopic interventions under general anaesthesia. Br J Anaesth 102:523-527

12. Hering R, Wenningmann I, Tchatcheva K, Van de Vondel P, Stressig R, Gembruch U, Kohl T (2008) A protocol for safe general maternofetal anesthesia during minimally invasive fetal surgery (abstract). Ultraschall Med 29:90

13. Shehata BM, Bare JB, Denton TD, Habib MN, Black JO (2006) Premature closure of the ductus arteriosus: variable response among monocygotic twins after in utero exposure to indomethacin. Fetal Pediatr Pathol 25:151-157

14. Kohl T, Szabo Z, Suda K, Harrison MR, Quinn TM, Petrossian E, Hanley FM (1997) Percutaneous fetal access and uterine closure for fetoscopic surgery: lessons from 16 consecutive procedures in pregnant sheep. Surg Endosc 11:819-824

15. Kohl T, Witteler R, Strümper D, Gogarten W, Asfour B, Reckers J, Merschhoff G, Marcus AE, Weyand M, van Aken H, Vogt J, Scheld HH (2000) Operative techniques and strategies for minimally invasive fetoscopic fetal cardiac interventions in sheep. Surg Endosc 14:424-430

16. Kohl T, Hering R, Van de Vondel P, Tchatcheva K, Berg C, Bartmann P, Heep A, Franz A, Müller A, Gembruch U (2006) Analysis of the stepwise clinical introduction of experimental percutaneous fetoscopic surgical techniques for upcoming minimally invasive fetal cardiac interventions. Surg Endosc 20:1134-1143

17. Luks FI, Deprest JA, Marcus M, Vandenberghe K, Vertommen JD, Lerut T, Brosens I (1994) Carbon dioxide pneumamniosis causes acidosis in fetal lambs. Fetal Diagn Ther 9:105-109

18. Gratacos E, Wu J, Devlieger R, Van de Velde M, Deprest JA (2001) Effects of amniodistension with carbon dioxide on fetal acid-base status during fetoscopic surgery in the sheep model. Surg Endosc 15:368-372

19. Pelletier GJ, Srinathan SK, Langer JC (1995) Effects of intraamniotic helium, carbon dioxide, and water on fetal lambs. J Pediatr Surg 30:1155-1158

20. Sayki Y, Litwin DE, Bigras JL, Waddel J, Konig A, Baik S, Navsarikar A, Rebeyka IM (1997) Reducing the deleterious effects of intrauterine $\mathrm{CO}_{2}$ during fetoscopic surgery. J Surg Res 69:51-54

21. Gratacos E, Wu J, Devlieger R, Bonati F, Lerut T, Vanamo K, Deprest JA (2002) Nitrous oxide amniodistention compared with fluid amniodistention reduces operation time while inducing no changes in fetal acid-base status in a sheep model for endoscopic fetal surgery. Am J Obstet Gynecol 186:538-543

22. Kohl T, Reckers J, Strümper D, Große Hartlage M, Gogarten W, Gembruch U, Vogt J, van Aken H, Scheld HH, Paulus W, Rickert CH (2004) Amniotic air insufflation during minimally invasive fetoscopic fetal cardiac interventions is safe for the fetal brain in sheep. J Thorac Cardiovasc Surg 128:467-471

23. Bruner JP, Richards WO, Tulipan NB, Arney TL (1999) Endoscopic coverage of fetal myelomeningocele in utero. Am J Obstet Gynecol 180(1 pt 1):153-158

24. Kohl T, Tchatcheva K, Weinbach J, Hering R, Kozlowski P, Stressig R, Gembruch U (2010) Partial amniotic carbon dioxide insufflation (PACI) during minimally invasive fetoscopic 
surgery: early clinical experience in humans. Surg Endosc 24(2):432-444

25. Fisk NM, Duncombe GJ, Sullivan MH (2009) The basic and clinical science of twin-twin transfusion syndrome. Placenta 30(5):379-390

26. Unmur A, van Gemert MJ, Nikkels PG (2003) Monoamniotic versus diamniotic monochorionic twin placentas: anastomoses and twin-twin transfusion syndrome. Am J Obstet Gynecol 189:1325-1329

27. Nikkels PG, Hack KE, van Gemert MJ (2008) Pathology of twin placentas with special attention to monochorionic twin placentas. J Clin Pathol 61:1247-1253

28. Mahieu-Caputo D, Dommerques M, Delezoide AL, Lacoste M, Cai Y, Narcy F, Jolly D, Gonzalez M, Dumez Y, Gubler MC (2000) Twin-to-twin transfusion syndrome: role of the fetal renin-angiotensin system. Am J Pathol 156:629-636

29. Galea P, Barigye O, Wee L, Jain V, Sullivan M, Fisk NM (2008) The placenta contributes to activation of the renin angiotensin system in twin-twin transfusion syndrome. Placenta 29:734-742

30. de Lia JE, Cukierski M, Lundergan D, Kochenour NK (1989) Neodymium: YAG laser occlusion of rhesus placental vasculature via fetoscopy. Am J Obstet Gynecol 160:485-489

31. Quintero RA, Morales WJ, Mendoza G, Allen M, Kalter CS, Giannina G, Angel JL (1998) Selective photocoagulation of placental vessels in twin-twin transfusion syndrome: evolution of a surgical technique. Obstet Gynecol Surv 53:S97-S103

32. Senat MV, Deprest J, Boulvain M, Paupe A, Winer N, Ville Y (2004) Endoscopic laser surgery versus serial amnioreduction for severe twin-to-twin transfusion syndrome. N Engl J Med 351:136-144

33. Quintero RA, Morales WJ, Allen MH, Bornick PW, Johnson PK, Kruger M (1999) Staging of twin-twin transfusion syndrome. J Perinatol 19:550-555

34. Roberts D, Neilson JP, Kilby M, Gates S (2008) Interventions for the treatment of twin-twin transfusion syndrome. Cochrane Database Syst Rev 23(1):CD002073

35. Kohl T, Tchatcheva K, Berg C, Geipel A, Van de Vondel P, Gembruch U (2007) Partial amniotic carbon dioxide insufflation (PACI) facilitates fetoscopic interventions in complicated monochorionic twin pregnancies. Surg Endosc 21:1428-1433

36. Lissauer D, Morris RK, Kilby MD (2007) Fetal lower urinary tract obstruction. Semin Fetal Neonatal Med 12:464-470

37. Clark TJ, Divakaran TG et al (2003) Prenatal bladder drainage in the management of fetal lower urinary tract obstruction: a systematic review and meta-analysis. Obstet Gynecol 102:367382

38. Pluto Collaborative Study Group, Kilby M, Khan K, Morris K, Daniels J, Gray R, Magill L, Martin B, Thompson P, Alfirevic Z, Kenny S, Bower S, Sturgiss S, Anumba D, Mason G, Tydeman G, Soothill P, Brackley K, Loughna P, Cameron A, Kumar S, Bullen P (2007) PLUTO trial protocol: percutaneous shunting for lower urinary tract obstruction randomised controlled trial. BJOG 114:904-905 e1-e4

39. Holmes N, Harrison MR, Baskin LS (2001) Fetal surgery for posterior urethral valves: long-term postnatal outcomes. Pediatrics 108(1):E7

40. Quintero RA, Johnson MP, Romero R, Smith C, Arias F, Guevara-Zuloaga F, Cotton DB, Evans MI (1995) In utero percutaneous cystoscopy in the management of fetal lower obstructive uropathy. Lancet 346:537-540

41. Welsh A, Agarwal S, Kumar S, Smith RP, Fisk NM (2003) Fetal cystoscopy in the management of fetal obstructive uropathy: experience in a single European center. Prenat Diagn 23:10331041

42. Sago H, Hayashi S, Chiba T, Ueoka K, Matsuoka K, Nakagawa A, Kitagawe M (2008) Endoscopic fetal urethrotomy for anterior urethral valves: a preliminary report. Fetal Diagn Ther 24:92-95

43. Clifton MS, Harrison MR, Ball R, Lee H (2008) Fetoscopic transuterine release of posterior urethral valves: a new technique. Fetal Diagn Ther 23:89-94

44. Johnson MP, Bukowski TP, Reitleman C, Isada NB, Pryde PG, Evans MI (1994) In utero surgical treatment of fetal obstructive uropathy: a new comprehensive approach to identify appropriate candidates for vesicoamniotic shunt therapy. Am J Obstet Gynecol 170:1770

45. Morris RK, Quinlan-Jones E, Kilby MD, Khan KS (2007) Systematic review of accuracy of fetal urine analysis to predict poor postnatal renal function in cases of congenital urinary tract obstruction. Prenat Diagn 27:900-911

46. Kilby MD, Daniels JP, Khan K (2006) Congenital lower urinary tract obstruction: to shunt or not to shunt? BJU Int 97:6-8

47. Craparo FJ, Rustico M et al (2007) Fetal serum $\beta 2$ microglobulin before and after bladder shunting: a 2-step approach to evaluate fetuses with lower urinary tract obstruction. J Urol 178:2576-2579

48. Jones KL, Smith DW, Hall BD, Hall JG, Ebbin AJ, Massoud H, Golbus MS (1974) A pattern of craniofacial and limb defects secondary to aberrant tissue bands. J Pediatr 84:90-95

49. Kanayama MD, Gaffey TA, Ogburn PL Jr (1995) Constriction of the umbilical cord by an amniotic band, with fetal compromise illustrated by reverse diastolic flow in the umbilical artery: a case report. J Reprod Med 40:71-73

50. Crombleholme TM, Dirkes K, Whitney TM et al (1995) Amniotic band syndrome in fetal lambs: I. Fetoscopic release and morphometric outcome. J Pediatr Surg 30:974-978

51. Quintero RA, Morales WJ, Phillips J, Kalter CS, Angel JL (1997) In utero lysis of amniotic bands. Ultrasound Obstet Gynecol 10:316-320

52. Hüsler MR, Wilson RD, Horii SC, Bebbington MW, Adzick NS, Johnson MP (2009) When is fetoscopic release of amniotic bands indicated? Review of outcome of cases treated in utero and selection criteria for fetal surgery. Prenat Diagn 29(5):457463

53. Stressig R, Tchatcheva K, Van de Vondel P, Berg C, Geipel A, Gembruch U, Kohl T (2008) Fetoscopic surgery in amniotic band syndrome: a tale of two cases and conclusions drawn for fetal selection (abstract). Ultraschall Med 29:120

54. Harrison MR, Adzick NS, Bullard KM, Farrell JA, Howell LJ, Rosen MA, Sola A, Goldberg JD, Filly RA (1997) Correction of congenital diaphragmatic hernia in utero: VII. A prospective trial. J Pediatr Surg 32:1637-1643

55. DiFiore JW, Fauza DO, Slavin R, Peters CA, Fackler JW, Wilson JM (1994) Experimental fetal tracheal ligation reverses the structural and physiological effects of pulmonary hypoplasia in congenital diaphragmatic hernia. J Pediatr Surg 29:248-257

56. Harrison MR, Mychaliska GB, Albanese CT, Jennings RW, Farrell JA, Hawgood S, Sandberg P, Levine AH, Lobo E, Filly RA (1998) Correction of congenital diaphragmatic hernia in utero: IX. Fetuses with poor prognosis (liver herniation, low lung-to-head ratio) can be saved by fetoscopic temporary tracheal occlusion. J Pediatr Surg 33:1017-1023

57. Chiba T, Albanese CT, Farmer DL, Dowd CF, Filly RA, Machin GA, Harrison M (2000) Balloon tracheal occlusion for congenital diaphragmatic hernia: experimental studies. J Pediatr Surg 35:1566-1570

58. Papadakis K, Luks FI, Deprest JA, Evrard VE, Flageole H, Miserez M, Lerut TE (1998) Single-port tracheoscopic surgery in the fetal lamb. J Pediatr Surg 3:918-920

59. Kohl T, Große Hartlage M, Kienitz D, Westphal M, Brentrup A, Aryee S, Achenbach S, Buller T, Bizjak GI, Stressig R, Van Aken H, Gembruch U (2003) Percutaneous fetoscopic tracheal 
balloon occlusion in sheep: a minimally invasive approach aimed at reduction of maternal injury during fetal surgery for diaphragmatic hernia. Surg Endosc 17:1454-1460

60. Jani JC, Nicolaides KH, Keller RL, Benachi A, Peralta CF, Favre R, Moreno O, Tibboel D, Lipitz S, Eggink A, Vaast P, Allegaert K, Harrison M, Deprest J, Antenatal-CDH-Registry Group (2007) Observed to expected lung area-to-head circumference ratio in the prediction of survival in fetuses with isolated diaphragmatic hernia. Ultrasound Obstet Gynecol 30:67-71

61. Gorincour G, Bouvenot J, Mourot MG, Sonigo P, Chaumoitre K, Garel C, Guibaud L, Rypens F, Avni F, Cassart M, MaugeyLaulom B, Bourliere-Najean B, Brunelle F, Durand C, Eurin D (2005) Prenatal prognosis of congenital diaphragmatic hernia using magnetic resonance imaging measurement of fetal lung volume. Ultrasound Obstet Gynecol 26:738-744

62. Kilian AK, Schaible T, Hofmann V, Brade J, Neff KW, Büsing KA (2009) Congenital diaphragmatic hernia: predictive value of MRI relative lung-to-head ratio compared with MRI fetal lung volume and sonographic lung-to-head ratio. AJR Am J Roentgenol 192:153-158

63. Harrison MR, Keller RL, Hawgood SB, Kitterman JA, Sandberg PL, Farmer DL, Lee H, Filly RA, Farrel JA, Albanese CT (2003) A randomized trial of fetal endoscopic tracheal occlusion for severe congenital diaphragmatic hernia. $N$ Engl J Med 349:1887-1888

64. Jani JC, Nicolaides KH, Gratacos E, Valencia CM, Doné E, Martinez JM, Gucciardo L, Cruz R, Deprest JA (2009) Severe diaphragmatic hernia treated by fetal endoscopic tracheal occlusion. Ultrasound Obstet Gynecol 34:304-310

65. Kohl T, Gembruch U, Tchatcheva K, Schaible T (2006) Comment: Current consequences of prenatal diagnosis of congenital diaphragmatic hernia by Deprest et al. (J Pediatr Surg 41:423430). J Pediatr Surg 41:1344-1355

66. Deprest J, Jani J, Van Schoubroeck D, Cannie M, Gallot D, Dymarkowski S, Fryns JP, Naulaers G, Gratacos E, Nicolaides K (2006) Author reply: Current consequences of prenatal diagnosis of congenital diaphragmatic hernia by Deprest et al. (J Ped Surg 41:423-430). J Pediatr Surg 41:1345-1346

67. Kohl T, Gembruch U, Filsinger B, Hering H, Bruhn J, Tchatcheva K, Aryee S, Franz A, Heep A, Müller A, Bartmann P, Loff S, Hosie S, Neff W, Schaible S (2006) Encouraging early clinical experience with deliberately delayed temporary fetoscopic tracheal occlusion for the prenatal treatment of lifethreatening right and left congenital diaphragmatic hernias. Fetal Diagn Ther 21:314-318

68. Randomized control trial of fetoscopic endoluminal tracheal occlusion with a balloon versus expectant management during pregnancy in fetuses with left-sided congenital diaphragmatic hernia and moderate pulmonary hypoplasia (TOTAL). NCT00763737. www.clinicaltrials.gov

69. Fetoscopic tracheal balloon occlusion in left diaphragmatic hernia. NCT00373438. www.clinicaltrials.gov

70. Peralta CF, Jani JC, Van Schoubroeck D, Nicolaides KH, Deprest JA (2008) Fetal lung volume after endoscopic tracheal occlusion in the prediction of postnatal outcome. Am J Obstet Gynecol 198:60.e1-60.e5

71. Percutaneous endoscopic tracheal plug/unplug for $\mathrm{CDH}$. NCT00768703. www.clinicaltrials.gov

72. Kilbride HW, Yeat J, Thibeault DW (1996) Preterm premature rupture of membranes prior to 22 weeks of gestation (ePPROM) may lead to severe pulmonary hypoplasia with poor chances of fetal survival. Am J Obstet Gynecol 175:675-681

73. Laudy JAM, Tibboel D, Robben SGF, de Krijger RR, de Ridder MAJ, Wladimiroff JW (2002) Prenatal prediction of pulmonary hypoplasia: clinical, biometric and Doppler velocity correlates. Pediatrics 109:250-258
74. Quintero RA, Romero R, Dzieczkowski J, Mammen E, Evans MI (1996) Sealing of ruptured amniotic membranes with intraamniotic platelet-cryoprecipitate plug (letter). Lancet 347: 1117

75. De Carolis MP, Romagnoli C, De Santis M, Piersigilli F, Vento $G$ (2004) Is there significant improvement in neonatal outcome after treating pPROM mothers with amnio-infusion. Biol Neonate 86:222-229

76. Tan LK, Kumar S, Jolly M, Gleeson C, Johnson P, Fisk NM (2003) Test amnioinfusion to determine suitability for serial therapeutic amnioinfusion in midtrimester premature rupture of membranes. Fetal Diagn Ther 18:183-189

77. Wilson JM, DiFiore JW, Peters CA (1993) Experimental fetal tracheal ligation prevents the pulmonary hypoplasia associated with fetal nephrectomy: possible application for congenital diaphragmatic hernia. J Pediatr Surg 28(11):1433-1439

78. Kohl T, Müller A, Franz A, Heep A, Willinek WA, Bartmann P, Gembruch U (2007) Temporary fetoscopic tracheal balloon occlusion enhanced by hyperoncotic lung distension: is there a role in the treatment of fetal pulmonary hypoplasia from early preterm premature rupture of membranes (ePPROM)? Fetal Diagn Ther 22:462-465

79. Kohl T, Geipel A, Tchatcheva K, Stressig R, Willinek WA, Gembruch U (2009) Life-saving effects of fetal tracheal occlusion on pulmonary hypoplasia from preterm premature rupture of membranes. Obstet Gynecol 113:480-483 2 pt 2

80. Lim FY, Crombleholme TM, Hedrick HL, Flake AW, Johnson MP, Howell LJ, Adzick NS (2003) Congenital high airway obstruction syndrome: natural history and management. J Pediatr Surg 38:940-945

81. Oepkes D, Teunissen AKK, Van de Velde M, Devlieger H, Delaere P, Deprest J (2003) Congenital high airway obstruction successfully managed with ex utero intrapartum treatment. Ultrasound Obstet Gynecol 22:437-439

82. Shimabukuro F, Sakumoto K, Masamoto H, Asato Y, Yoshida T, Shinhama A, Okubo E, Ishisoko A, Aoky Y (2007) A case of congenital high airway obstruction syndrome managed by ex utero intrapartum treatment: case report and review of the literature. Am J Perinatol 24:197-201

83. Crombleholme TM, Albanese CT (2001) The fetus with airway obstruction. In: Harrison MR, Evans MI, Adzick NS, Holzgreve W (eds) The unborn patient, 3rd edn. WB Saunders, Philadelphia, pp 357-371

84. Kohl T, Van de Vondel P, Stressig R, Wartenberg HC, Heep A, Keiner S, Müller A, Franz A, Fröhlich S, Willinek W, Gembruch U (2009) Percutaneous fetoscopic laser decompression of congenital high airway obstruction syndrome (CHAOS) from laryngeal atresia via a single trocar: current technical constraints and potential solutions for future interventions. Fetal Diagn Ther 25:67-71

85. Walsh DS, Adzick NS, Sutton LN, Johnson MP (2001) The rationale for in utero repair of myelomeningocele. Fetal Diagn Ther 16:312-322

86. Bruner JP (2007) Intrauterine surgery in myelomeningocele. Semin Fetal Neonatal Med 12:471-476

87. Copeland ML, Bruner JP, Richards WO, Sundell HW, Tulipan NB (1993) A model for in utero endoscopic treatment of myelomeningocele. Neurosurgery 33:542-544

88. Tulipan N, Bruner JP (1998) Myelomeningocele repair in utero: a report of three cases. Pediatr Neurosurg 28:177-180

89. Farmer DL, von Koch CS, Peacock WJ, Danielpour M, Gupta N, Lee H, Harrison MR (2003) In utero repair of myelomeningocele: experimental pathophysiology, initial clinical experience, and outcomes. Arch Surg 138:872-878

90. Adzick NS, Sutton LN, Crombleholme TM, Flake AW (1998) Successful fetal surgery for spina bifida. Lancet 352:1675-1676 
91. Tubbs RS, Chambers MR, Smyth MD, Bartolucci AA, Bruner JP, Tulipan N, Oakes WJ (2003) Late gestational intrauterine myelomeningocele repair does not improve lower extremity function. Pediatr Neurosurg 38:128-132

92. Danzer E, Gerdes M, Bebbington MW, Sutton LN, Melchionni J, Adzick NS, Wilson RD, Johnson MP (2009) Lower extremity neuromotor function and short-term ambulatory potential following in utero myelomeningocele surgery. Fetal Diagn Ther 25:47-53

93. Holmes NM, Nguyen HAT, Harrison MR, Farmer DL, Baskin LS (2001) Fetal intervention for myelomeningocele: effect on postnatal bladder function. J Urol 166:2383-2386

94. Carr MC (2007) Fetal myelomeningocele repair: urologic aspects. Curr Opin Urol 17:257-262

95. Yoshizawa J, Sbragia L, Paek BW, Sydorak RM, Yamazaki Y, Harrison MR, Farmer DL (2003) Fetal surgery for repair of myelomeningocele allows normal development of the rectum in sheep. Pediatr Surg Int 19:162-166

96. Yoshizawa J, Sbragia L, Paek BW, Sydorak RM, Yamazaki Y, Harrison MR, Farmer DL (2004) Fetal surgery for repair of myelomeningocele allows normal development of anal sphincter muscles in sheep. Pediatr Surg Int 20:14-18

97. Paek BW, Farmer DL, Wilkinson CC, Albanese CT, Peacock W, Harrison MR, Jennings RW (2000) Hindbrain herniation develops in surgically created myelomeningocele but is absent after repair in fetal lambs. Am J Obstet Gynecol 183:1119-1123

98. Tulipan N, Sutton LN, Bruner JP, Cohen BM, Johnson M, Adzic NS (2003) The effect of intrauterine myelomeningocele repair on the incidence of shunt-dependent hydrocephalus. Pediatr Neurosurg 38:27-33

99. Bruner JP, Tulipan N, Reed G, Davis GH, Bennet K, Luker KS, Dabrowiak ME (2004) Intrauterine repair of spina bifida: preoperative predictors of shunt-dependent hydrocephalus. Am J Obstet Gynecol 190:1212-1305

100. Management of Myelomeningocele Study (MOMS). NCT00060606. www.clinicaltrials.gov

101. Kohl T, Große Hartlage M, Kienitz D, Westphal M, Buller T, Aryee S, Achenbach S, Gembruch U, Brentrup A (2003) Percutaneous fetoscopic patch coverage of experimental lumbosacral full-thickness skin lesions in sheep: a minimally invasive technique aimed at minimizing maternal trauma from fetal surgery for myelomeningocele. Surg Endosc 17:1218-1223
102. Kohl T, Gembruch U (2008) Current status and prospects of fetoscopic surgery for spina bifida in human fetuses (response to Fichter et al.: Fetal spina bifida repair: current trends and prospects of intrauterine neurosurgery. Fetal Diagn Ther 23:271-286). Fetal Diagn Ther 24:318-320

103. Kohl T, Tchatcheva K, Merz W, Wartenberg HC, Heep A, Müller A, Franz A, Stressig R, Willinek W, Gembruch U (2009) Percutaneous fetoscopic patch closure of spina bifida aperta in the human: advances in fetal surgical techniques may now obviate the need for early postnatal neurosurgical intervention. Surg Endosc 23:890-895

104. Kohl T (2008) Iatrogenic fetal membrane damage from complex fetoscopic surgery in human fetuses might not be amenable to simple closure by collagen plugs. Prenat Diagn 28:876-877

105. Kohl T (2008) Mending the tieniest hearts: an overview. In: Yagel S, Silverman NH, Gembruch U (eds) Fetal Cardiology, 2nd edn. Martin Dunitz-Taylor \& Francis Group, London, New York

106. Kohl T, Müller A, Tchatcheva K, Achenbach S, Gembruch U (2005) Fetal transesophageal echocardiography: clinical introduction as a monitoring tool during fetal cardiac intervention in a human fetus. Ultrasound Obstet Gynecol 26:780-785

107. Kohl T, Breuer J, Heep A, Wenningmann I, Weinbach J, Gembruch U (2007) Fetal transesophageal echocardiography during balloon valvuloplasty for severe aortic valve stenosis at $28+6$ weeks of gestation. J Thorac Cardiovasc Surg 134:256257

108. Kohl T, Westphal M, Strümper D, Achenbach S, Halimeh S, Petry P, Aryee S, Buller T, Aleksiene R, Asfour B, Witteler R, Vogt J, Van Aken H, Scheld HH (2001) Multimodal fetal transesophageal echocardiography for fetal cardiac intervention in sheep. Circulation 114:1757-1760

109. Kohl T, Herberg U (2010) Fetoscopic transesophageal electrocardiography - A minimally invasive tool for cardiac monitoring, diagnostics and intervention in human fetuses. Ped Cardiol (in press)

110. Tsao K, Feldstein VA, Albanese CT, Sandberg PL, Lee H, Harrison MR, Farmer DL (2002) Selective reduction of a cardiac twin by radiofrequency ablation. Am J Obstet Gynecol 187:635-640 